\title{
Students' letters to patients as a part of education in family medicine
}

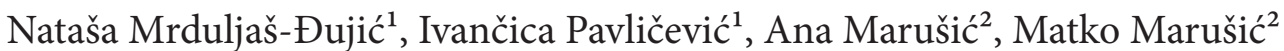 \\ ${ }^{1}$ Department of Family Medicine \\ School of Medicine, University of Split \\ Split, Croatia \\ ${ }^{2}$ Department of Research in Biomedicine \\ and Health, School of Medicine \\ University of Split, Split, Croatia \\ Corresponding author: \\ Nataša Mrduljaš-Đujić \\ Department of Family Medicine \\ Split University School of Medicine \\ Šoltanska 2 \\ 21000 Split \\ Croatia \\ md.natasa@gmail.com

\begin{abstract}
Family medicine fosters holistic approach to patient-centered practice. Current medical curriculum in Croatia does not have well-structured courses or tools to prepare medicals students for successful communication with the patient and for building lasting and beneficial doctor-patient relationship. We explored the value of students' practice in writing letters to patients about their illness as a way of building personal and compassionate relationship with patients. Sixth year students at the School of Medicine in Split wrote letters to the patients from consultations under the supervision of the supervisor in a family medicine practice. Structured teaching of communication with the patient brings family medicine back to what has actually always been its main part - communication and doctor-patient relationship. Our future aim is to develop students' letters to patients as a new tool in the family medicine course examination. Moreover, we will investigate
\end{abstract} \\ how they can be used in everyday practice of family medicine.
}

Tel.: + 38521631292

Fax: + 38521631292

Received: 19 December 2011

Accepted: 8 February 2012

Copyright (c) 2012 by

Academy of Sciences and Arts

of Bosnia and Herzegovina.

E-mail for permission to publish:

amabih@anubih.ba
Key words: Letter to the patient, Family practice, Communication, Doctor patient relationship.

\section{Introduction}

Word comes first and then cure!
Hippocrates

At present, medical profession seems to be more concerned about form and technology than about individual interaction with a patient as a human being: "To be intellectually free, sometimes we have to write the diagno- sis, medical history, state facts and figures, and then we have time for the patient. First, we must satisfy the system. Let's do the paperwork, then we can be doctors" (1). On the other hand, family medicine fosters holistic, bio-psycho-social approach to patient-centered practice. It seeks to identify the patient's priorities and concerns, and includes patients 
(to the extent they wish) to make decisions regarding their health problems (2).

\section{Physician-patient relationship}

The key to the health care system is the relationship between the patient and the physician in the doctor's office or by the hospital bed, where we deal with the patient, not just his or her illness $(1,3)$. The belief that the relationship between doctor and patient determine the behavior of the whole system has changed the understanding of the system as something external and imposed $(1,4)$.

There are four basic levels of relationship in the doctor-patient relationship (1). The first level involves doctor as a mechanic who repairs some damage (illness, broken bones, etc) and the patient who passively undergoes such repair. The second level corresponds to that between the teacher and the student, where the patient follows the recommended care plan and changes his or her behavior. At the third level, physician is like a coach whose actions change the patient's attitude toward health or illness. Finally, the forth level involves active collaboration between the patient and the physician, where they both become enriched through joint work.

Both patients and physicians agree that their current relations are generally of the first or second level. They may aim to reach the third or fourth level, but this requires creation of specific circumstances, as well as learning and adaptation on both sides their goal is "to light a fire, not to fill a barrel" (1). Using their own knowledge and experiences, the physician and the patients should develop a partnership in which the physician helps the patients to become aware of what they actually want with their health, and to develop their own systems of caring for it. Health and personal responsibility are closely linked; with greater responsibility for own health, it is easier to accept new and higher quality knowledge $(1,5)$.

\section{Communication}

The basic elements of medical training are communication skills and evidence-based medicine. However, experience tells us that we are not very successful in the acquisition and application of communication skills. There are more and more patients who do not understand our advice and who do not know how to look for further information regarding their health $(2,3)$.

There is no distinctive professional style of communication as a product of medical education in Croatia. Communication skills are taught as a part of different courses during the curriculum, but the teaching is not wellstructured in family medicine course in the sixth year, when students attend rounds in family medicine offices. The consequence of this is that our professional communication very much depends on our personalities rather than on the skills we learned during medical school and later professional training $(2,6)$.

\section{Physicians' personal letters to the patient}

The lack of structured tools for promoting empathy and communication in family medicine teaching prompted us to explore the practice of writing letters to patients about their illness. There are many examples of written communication between physicians/health professionals and patients. For example, the Firefly Project (7) has a large archive of letters written by medical students and community teenagers to patients with life-threatening illness. The patients greatly appreciated this experience, as one of them wrote: "At a time when a sudden illness has made me sensitive to those who did not understand my story, I was encouraged by doctors who have worked hard to save me. I 
felt the impulse to give all of myself. Writing You allowed me to reconnect with parts of myself that I thought were lost forever, and for that I thank you." (7).

Letters to families of patients were also used as a strategy in nursing education, and reported benefits for students, faculty and patients (8).

Finally, the project of the National Health Service (NHS) in Great Britain investigated the usefulness of letters to the patient after specialist consultation (9). Letters were very well accepted by patients, especially those addressed personally, rather than those written to a family physician. Likewise, it was necessary to write simple, structured and understandable letter tailored to the patient and his or her needs (9).

\section{Students' letters to patients in teaching family medicine at the Medical school in Split}

In the Croatian health care system, discharge letter a patient receives when released from the hospital is the only written communication for him or her and is actually intended for the primary care physician - family doctor. The letter is formally written and in very professional language, with the focus on all the procedures and findings related to the patient. The letter lacks any personal message, as it is common on other health care systems, where it begins with "Dear colleague..." (9).

Based on the experience from previous studies of letters as communication channel between health care and patients (7-9), we used letter writing to teach communication skills to medical students attending family medicine course in the sixth year of their curriculum. During their practical work in family medicine offices, we asked them to write letters to selected patients whom they had examined during practice.
The goal of student writing letters to the patient was to: 1) develop a new instrument for the evaluation of the examination in family medicine; 2 ) explore how such an instrument (tool) can be used in everyday practice; 3) develop an internal dialogue in a family medicine office to better understand the patient's care and concerns, needs and priorities at the time of disease; and 4) develop students' communication skills in relation to the patient. Finally, we thought that the patients would have the greatest benefit as they would receive a document that would help them to understand their illness and benefit from a very personal interaction with and support by a medical professional.

After the examination of a patient with a suitable medical history, the student was advised by the supervisor (family medicine physician in the office) to compose a personal letter to the patient. The students were asked to write in simple, understandable language about the following elements:

1. Basic information on age, gender, social and educational status of the patient and the diagnosis;

2. Description of symptoms and reasons for the visit to the office;

3. Relevant sections of the medical history, which are, in the opinion of the student, important for the present condition of the patient;

4. Integration of the illness history and current problem of the patient; and

5. Recommendations for treatment and lifestyle, with explanations (what students think is important for the patient in this state and how he or she should behave concerning health).

The following excerpts from two student letters illustrate students' ability to combine knowledge and empathy.

Student's letter to a female patient aged 76 , retired, suffering from arterial hypertension: 
Dear Mrs. L, ...

Thank you for your time and your appreciation of our assignment to write a letter to the patient. I am writing this letter to briefly explain your illness and give you advice/recommendations on how to better control it and live with it, so it would not be leaving consequences to your health. Your illness, or better to say - condition, is called primary arterial hypertension.

...

Your heart pumps blood into the blood vessels that can narrow or expand, depending on the needs of the organism. The blood in the vessels needs to be under some pressure in order to flow through your body. If the pressure is within normal limits of $140 / 90 \mathrm{mmHg}$, it is not harming the blood vessels. When the pressure rises above this limit and if this condition lasts for years, it damages the heart and the blood vessels. The downside of all this is that there are no significant signs that make you see or feel that something was wrong. Nevertheless, the disease is present and somewhat damages the body, so is often called the "silent killer" because it can eventually cause life-threatening conditions like heart attack or stroke.

$\ldots$

I have seen during our meeting at the office that you are a warm, caring and positive person, and these are the qualities that will surely help you cope with life's everyday adversities. Stress is responsible for many conditions and diseases and thus plays an important role in your hypertension. Deal with it in a way that suits you best. Do not let it take control of your life. Spend your time with people you like, talk about topics that interest you, think positive and take every obstacle as an opportunity for growth. Your life is in your hands and if you do not care for yourself other will not be able to do it instead of you. You have the power to make your life better, stronger and healthier.

Please accept my cordial greetings, in the hope that this letter will help you understand your disease and find the best way to live with it. I wish you all the best in life. Sincerely Yours....

Letter to a female patient aged 56, accountant by profession, suffering from a duodenal ulcer:

Now I will briefly present the basic features of your illness.

The main symptom of an ulcer in the duodenum is the pain and discomfort in the stomach. The pain is caused by hungriness and the pain usually disappears after eating. The characteristic of these patients is to be hungry at night because it leads to the onset of symptoms. The appearance of black stools or vomiting blood indicates the occurrence of disease complications when medical help should be sought immediately. Ninety percent of the patients with ulcer also have the infection with a bacterium called Helicobacter pylori, which contributes to disease development and therefore should be removed from the body.

Several types of drugs are used in the treatment of duodenal ulcer. These drugs can relieve the symptoms, speed the healing of the ulcer and prevent recurrence of the disease. Other drugs can reduce stomach acid and protect the mucous membranes. The therapy is essential to carry out the treatment of the infection with Helicobacter pylori.

Since we confirmed the existence of these bacteria in Your stomach, I advise you to take an appropriate therapy.

This therapy consists of a combination of three drugs. One of them reduces the se- 
cretion of stomach acid, which adversely affects the development of the disease, and the other two drugs are antibiotics that act on the bacterium Helicobacter pylori. The therapy lasts 14 days and has $85-95 \%$ success. After therapy, it is necessary to make a test that will confirm whether or not the bacteria were removed. The test is performed 5-6 weeks after the end of therapy. Then we will, in consultation with you, decide on further actions.

I hope that I had, at least in part, clarified doubts regarding your medical condition. If you are still unclear about the disease, I am available to answer your questions and suggestions.

The following excerpts from two letters illustrate how the empathy between the doctor and the patient helps the patient to feel secure and have trust in the treatment process.

Letter to a male patient aged 72 , carter by profession, retired, married, with two daughters and a son, and two grandchildren; suffering from moderate depression and essential hypertension:

Dear Mr. F,

I remember how you told me that, after the consultation in our office, you were not much better and were still waiting for the situation to be improved. Now I am writing to you to give you some advice but you have to understand one thing: the best person to help you is you yourself.

Do you remember when we talked and you were glad that you received attention and care? Do you remember how you laughed when you met me and my colleague while you were picking up granddaughter from kindergarten? We all need attention and we all need to feel needed, even for a few moments in the day. You know it for sure, because while you were working you had that feeling. What you do not understand now is that you are needed even now, but in a different way. You have a family that loves you and needs your advice, your son needs your appreciation for the work that you gave him, and your wife needs your support.

I'm sure you still have dreams that you wanted to accomplish, like your wife too.

...

Remember that you will be better only when you decide it by yourself. Please, turn towards everyday things that make you happy as much as possible.

Sincerely Yours....

Letter to a female patient aged 71, retired, with primary school education; suffering from moderate depression, gastritis, liver cirrhosis, elevated arterial pressure, cardiac arrhythmias and lumbosacral syndrome.

The problem that brought you to the office this time was the blood in your urine. You have already had mild bladder infection, and you felt some kind of similar problems last few months. The first thing to be done is to test the urine, and when we have results we should then know more about it. You told me that you were afraid because you didn't feel pain when you found the blood in your urine, because you had been told that "if there is pain, it is not serious problem". Obviously this would mean cancer. Please do not listen and believe such statements because they are not true and no such rule exists. Of course none of us is immune to malignant disease, and each of us can get it, but they are, fortunately, not frequent. Inflammation is much more frequent you have experienced it, and seem to be prone to them. 
Do not be afraid of anything in advance and try not to imagine the worst possibilities, because if it is so, no one would, for example, walk down the street because of the fear to be accidentally hit by a car, although the chances of it are small. You received, in a short time, many bad news about your health and it is not easy to deal with this without suffering. I understand that you have sense of loneliness because the members of your family live their own lives and are preoccupied with their problems. However, please, try to find motivations for joy in your life. It does not have to be anything big and you don't need, while you recover from the shocks that you have experienced, to burden yourself with high expectations. Take your time to slowly get over the news and continue to live. However, in the morning when you wake up, try to remember at least one small positive thing that will keep the day: spending time with your grandkids, if you enjoy a walk on a beautiful day, favorite shows, flowers that you buy yourself or whatever makes you happy. Your problems are not big and you can work to resolve them.

The value of your life is great and a lot can affect another person's life. You were my first patient with whom I had a full consultation of my own, and I will never forget you. Did you, when you woke up on Thursday morning, think that you would be someone's first in his live - in your case my first patient? You are a strong and special person, so please try not to think only about negative things in life when you do a lot of positive things even when there is no hope. I wish you lot of happiness and good health,

Sincerely Yours....

Students were also able to deliver useful and professionally founded recommendations to patients.
Letter to a male patient aged 52, economist by profession, suffering from diabetes.

...

I will point out one possible complication of diabetes - diabetic foot, because you yourself can do much to prevent its occurrence. Check your feet daily for cuts, blisters, sores, infections or unusual markings. When you do that, use a mirror if you cannot raise your foot.

Cut your nails straight. Wash your feet every day, and dry them carefully, especially the area between the toes. Avoid using lotions in that area. Change socks every day.

Buy shoes late in the afternoon. Then the feet are more swollen. This will prevent that you wear tight, uncomfortable shoes.

...

Students' letters were evaluated as a part of their family medicine course examination. The evaluation addressed five aspects of the letters: 1) appropriateness and clarity of the description of the illness/condition; 2) knowledge about the illness/condition; 3) quality and usefulness of the recommendations; 4) courtesy and empathy demonstrated in the letter and 5) skill of verbal expression. The rating was performed by three family physicians - supervisors in the practice in family medicine offices, blinded to the identity of the students.

\section{Comment}

We were very satisfied with the results of our experiment in family practice. Students got high marks on their exam and we had a chance to re-examine our skills in communicating with the patient and the knowledge about specific problems students wrote about. We learned that when the patients spent more time in consultation with the 
student and his or her supervisor and when they receive students' letters afterwards, they felt better prepared to understand and accept their illness or condition. We also learned that courtesy and empathy were equally important to the patient as the competence in dealing with objective symptom, physical examination and diagnostic accuracy.

The first reactions from patients were very positive. Some of them were afraid that the letters would bring bad news, and sometimes they complained that the letters contained too many technical terms which confused them. Many comments were optimistic and personal:

"I periodically go back to read the letter again, and it helps me."

"I'm so glad they wrote it because I'm interested to learn how to help myself."

"I understood everything in the letter and now I know about my disease better than before."

"I found the letter very comforting and reassuring."

"This approach to the patient is very important. Thank you."

Perhaps in future the patients will have their history at the tip of their fingers on a keyboard or some e-application $(10,11)$. For the time being, we believe that simple, personal letters are valuable prescriptions for the satisfaction of patients and doctors in their joint work for health.

How is it really to be a doctor? What gives meaning to his work?

The art of medicine consists not only of how to comply with the rules of profession. What a man does in medical practice, and yet beyond what is strictly medical, that personal, human, it makes sense of that work and makes man in it irreplaceable.

"Doctor and the Soul"

Viktor E. Frankl
Authors' contributions: All four authors contributed to Conception and design; Acquisition, analysis and interpretation of data; Drafting the article; and Revising it critically for important intellectual content.

Conflict of interest: The authors declare that they have no conflict of interest. This article was not sponsored by any external organisation.

\section{References}

1. Kaeufer K, Scharmer CO, Versteegen U. Breathing life into a dying system. Reflections. The SoL Journal. 2003;5:1-10.

2. Gillies J, Mercer SW, Lyon A, Scott M, Watt GCM. Distilling the essence of general practice: a learning journey in progress. Br J Gen Pract. 2009;59:167-76.

3. Ožvačić Adžić Z, Katić M, Kern J, Lazić Đ, Cerovečki Nekić V, Soldo D. Patient, physician, and practice characteristics related to patient enablement in general practice in Croatia: Cross-sectional survey study. Croat Med J. 2008;49:813-23.

4. Egnew TR, Mauksch LB, Greer T, Farber SJ. Integrating communication training into a required family medicine clerkship. Acad Med. 2004;79:737-43.

5. Duffy FD, Gordon GH, Whelan G, Cole-Kelly K, Frankel R, Buffone N, et.al. Assessing competence in communication and interpersonal skills: the Kalamazoo II report. Acad Med. 2004;79:495-507.

6. Teutsch C. Patient-doctor communication. Med Clin North Am. 2003;87:1115-45.

7. Dolan B, Goren N, Perlis C. Epistolary medicine. Lancet. 2009;374:1588-9.

8. Freed PE, McLaughlin DE, SmithBattle L, Leander S, Westhus N. Therapeutic letters in undergraduate nursing education: ideas for clinical nurse educators. Nurse Educ Today. 2010;30:470-5.

9. Roberts NJ, Partridge MR. How useful are post consultation letters to patients? BMC Med. 2006:4:2.

10. Christner JG, Stansfield RB, Schiller JH, Madenci A, Keefer PM, Pituch K. Use of simulated electronic mail (e-mail) to assess medical student knowledge, professionalism and communication skills. Acad Med. 2010;85:S1-4.

11. Barnhart A, Lausen H, Smith T, Loop L. Electronic health communication: an educational application for this principle of the patient-centered medical home. Fam Med. 2010;42:322-6. 